УДК 331

DOI: 10.17277/voprosy.2016.04.pp.121-128

\title{
THE MICRO-EFFECT OF SOCIAL NETWORKING ON ENTERPRISE HUMAN RESOURCES MANAGEMENT
}

\author{
M. Shen \\ School of Economics, Shandong Normal University, Jinan, China \\ Reviewed by Doctor of Economics Sciences, \\ Professor N. V. Zlobina
}

Keywords: enterprise efficiency; human resources management; social networking services.

\begin{abstract}
Social Networking (Services) pushes the tools of enterprise human resources management to new levels. Social Networking (Services) may produce both positive and negative effects on implementation of enterprise human resources management, including staff recruitment, cross-cultural communication, performance evaluation and team construction.
\end{abstract}

The competition among modern enterprises is the competition of the core competitiveness. The non-core and transactional work is more likely to be outsourced as the wide use of social networking services is available to ensure the efficient operation of the overall company architecture. The main objective of human resources management is to find the right combinations of skilled people and create value effectively, meanwhile ensuring that staff are appropriately trained and encouraged to fulfill the task. The impacts of social networking services on human resources management are related not only to technical level such as network recruitment but to the enterprise's organization culture and the way that staff do their jobs. For enterprises, they can make rational use of new tools and new platforms that social networking services supplied, and then achieve better results in many respects, such as staff recruitment cross-cultural communication performance evaluation and team construction. For employee, job-related information experience and technique can be obtained by social networking services, where they can set up their own networking and expert base, thereby achieving relatively efficient technical support and resource support at a lower time cost.

Шень Минвей - доцент Шаньдунского педагогического университета, заведующий кафедрой «Коммерция», e-mail: casteroy@qq.com, г. Цзинань, Китайская Народная Республика.

УНИВЕРСИТЕТ им. В. И. ВЕРНАДСКОГО. №4(62). 2016. 


\section{The Effect of Social Networking Services on Human Resources Management}

With the development of technology, social networking services have becoming a key bond between work and life. According to 2011 Kelly Services Global Employee Index Research Report, $81 \%$ of employees used social networking services everyday, of whom $57 \%$ thought social networking services could improve the work and $21 \%$ of them found their job through social networking services. At the same time, Facebook and Linkedin are nationally accepted and we expect more enterprises to use social media tools, including internal network, real-time chat and collaboration. As mobile phones have been the main medium of internet, this kind of significance has grown exponentially. According to IDC (International Documentation Center) in China, 527 million people used mobile phones to access the Internet in 2014, which accounted for $83.4 \%$ of the overall netizens, more than that of PC-based users which accounted for $80.9 \%$. Mobile phones have become the first Internet-enabled terminal device. This also means that human resources management is confronted with new adjustments and breakthroughs.

With the popularization of the Internet, practices show that the enterprises, which have great human resources management, are also adept at using the Web in management. The so-called social networking services are the important carrier of social bonds. Business contact external to the enterprise and human resources management internal to the enterprise are important components of it.

\section{Innovation Tools of Human Resources Management Based on Social Networking Services}

According to DLA Piper's figures released in 2011, $40 \%$ of enterprises used social networking services in talent recruitment, staff communication and talent retention, $30 \%$ of which used social networking services for team building. This means that social networking services made a great contribution to human resources management of enterprises.

In the Chinese Internet Industry Size Ranking, Tencent ranked the first place, as the major social networking and communication platform of whitecollar workers. In addition, according to the report published by Mckinsey in 2012, the undeveloped commercial value of social technologies would be as high as 1.3 trillion. However, there is only a small percentage of enterprises making good use of social networking. In other words, the development of social networking offers a big opportunity for the development of human resources management.

The development of the social network makes the speed of information transmission and utilization speed up rapidly. This will have a significant impact on recruitment, communication, performance evaluation and team construction, while also may offer a new tool for human resources management.

Employee recruitment. Employee recruitment has been the main application field of social networking for human resources management. Employee recruitment through social networks not only makes the mutual 
selection more convenient, but also ensures the efficiency of human resources management. At the same time, for individuals, a social network is an important tool for maintaining professional contacts.

Traditional network recruitment takes a long time, and only recruitment channel diversification can solve the problem of the efficiency of recruitment. Human resources management has to confront the challenges of recruitment channel diversification and fragmentization. The increasingly complicated present situation needs using advanced software tools to manage the external channels, to improve the efficiency of enterprise recruitment, and to provide enterprises with effective human resources management support.

Traditional network recruitment is one-way, but the recruitment based on social networks is two-way. After the enterprise provides the recruitment information, the two sides have interaction, which makes the information more symmetrical and helps both sides make the best choice.

Traditional mode of network recruitment is targeted at job seekers who have transformation requirement, making room for the development of human resources. LinkedIn's membership has boomed to 313 million over the past three years, with two-thirds living outside the United States. Traditional recruitment is arranged when the employees have job requirements, but LinkedIn can provide potential "job seekers", a group which already have stable work but will choose job hopping when they have suitable choice. This kind of "job seekers" accounted for 60 percent of membership.

At the same time, with the development of social networking, most of the career opportunities have not been advertised publicly, but through internal employee referrals. From the statistical results, this approach not only ensured the quality of recruitment but also reduced the cost.

Cross-cultural communication. Technological progress has always influenced the way people communicate. For a multinational company or a national company, due to the differences of geographical environment, ethical culture, religion, political and legal environment, etc, the employee view of value and career objectives makes a difference. Through social networks, one can effectively solve communication barriers of distance and time, ensure that employees can make cross-cultural communication at a low cost, and thus seek common ground, integrating individual values with enterprise culture, achieving their business goals by increasing cooperation. This is also the major features of enterprise humanistic care.

Most striking attribute of social media is to avoid all sorts of barriers in modern society, give people the opportunity to speak freely, and reach the state of rational resource allocation. The heavy use of online communication platform has made the world the so-called global village. The enterprise culture can be spread in a far more rapid and pervasive way. Audiences absorb and integrate the enterprise culture after they understand it, then internalize it as employee sharing culture, thus effectively ensuring the consistency of personal goals and enterprise goals. Boundaryless organization form established the link both internally and externally. Communication platform naturally makes the enterprise managers and ordinary employees as close as possible. They can have equal communication and even brainstorming, which has replaced the 
traditional imperative way of communication, and made managers and employees communicate more effectively. In addition, the enterprise internal communication platform makes the internal information public, which can avoid suspicions and improve the working efficiency. What is the most outstanding of social networking site is that it helps to avoid various kinds of communication disorders in modern society, increase the chances of speaking up. This is also a kind of rational distribution of resources, while celebrity or comments are a kind of effective means to promote learning. The group advocate within enterprise can provide employees with posts of celebrity or practicability in internal communication group, helping them to study and drawing in pursuit of their efficiency and less detours.

The vigorous development of social networking also makes online virtual enterprises focus on their core competitiveness, and the human resource management of the enterprise is more targeted. Customer and enterprise, enterprise and enterprise can keep communication through social networking sites anytime and anywhere. This can reduce transaction costs and harmful effects. If a product can only be finished by the collaboration of different enterprises, this makes the enterprises a dynamic alliance. With the help of the networking technology, human resources department can communicate with employees about the work targets specifically and effectively, make use of the key resources, and take the comparative advantages to start manufacture effectively, leading to minimum the costs of each link and maximum the profits in the whole dynamic alliance.

The performance appraisal. Online communication has enriched both the content and the ways of surrounding performance appraisal. The efforts that enterprise managers and employees make for better work are related performance. However, it is hard to quantity and put high requirements on of human resource management. To some extent, online communication platform solves the problems of imperceptibility. Chatting records offer another perspective on employees' efforts. The affirmation and encouragement can inspire more employees to join in enterprise internal communication platform activities and form a virtuous cycle that finally realizes the maximum use of enterprise internal communication platform.

Team building. In the Internet age, the connection between an individual and organization is becoming more diverse but its intensity is relatively weak. This requires using social networks. The trend of flattening is more and more obvious, which also means that the number of subordinates has increased dramatically. Therefore, the design of human resource management system will be averted to series of motivation behavior like potential exploitation, diverse needs satisfaction and organizational citizenship behavior guidance to avoid opportunism of employees.

In addition, the rapid development of online games also has positive impacts on enterprise human resource management. The participation of enterprise staff is changing the enterprise human resource management model. All online games are nothing more than the team and personal heroism, for example, in the same game, the truth of assembling a team is personal configuration, which has the same target and their personalities complement 
each other. The staff configuration in human resource management is quite similar. Players fight against the enemy or complete a particular task as a whole team, and players often belong to the same company or even work in the same office. Cooperation in the social networks reflected in real life can develop collaboration between employees, strengthen their team building, and improve the cohesion of enterprise. "Staff" in the online team game can have communication outside their work, therefore improve their relations, enhance trust, and boost the work efficiency of the team.

Many team games develop teamwork spirit. Firstly, an informal group can be formed easily in the participation of online games. The informal group plays a special role in the actual management, where members will further enhance mutual understanding, improving collaboration and trust at work. Secondly, online games can be a low-cost team development training. Compared with real team development training, it has a lower cost, flexible forms, takes less time and requirements. White-collar workers can better accept this. Online games are useful for development of team spirit as a virtual form that can be used for practicing of employees' relevant qualities. Moreover, online games are more and more widely used to relieve pressure after the work. Online games outside the office let everyone effectively alleviate the pressure of the contradiction in the virtual world.

\section{Social Network Putting Forward New Challenges to Human Resource Management}

The influence of technological progress is often complicated. Although the development of Internet technology and social networking has reduced people's communication barriers, it also has some problems which enterprise human resource management needs to cope with.

When recruiting employees through social networks, the quality of recruitment information is very important. Apart from being accurate and efficient, it must be based on individual needs. A new recruitment platform based on social networks can be developed using a traditional recruitment website.

If employees become aware of the difference in values in network communication, they may produce prejudice against those who have different values. Discrimination and exclusion are easy to occur. This puts forward new challenges to enterprise human resource management. Differences in values affect cross-cultural communication. Thus, it is important to eliminate cultural differences in communication through various means. In dealing with international affairs, a multinational company covers coordination costs. This is one of the important causes of the failure of transnational mergers and acquisitions. The individual behavior and speech in the non-working environment may also have a negative impact on the enterprise. Yet there are many enterprises' regulations forbidding the use of social networks. In some countries and regions, these enterprises are likely to face charges of violations of civic rights.

To sum up, social networks also can bring negative effects to enterprise human resource management, resulting in some new problems of management. Firstly, all kinds of enterprise's information will be spread through social 
networking sites, including negative information. Secondly, the problem of quality of network communication also cannot be ignored. Discussion topics on network communication platforms are often not restricted. When employees choose an interesting topic, which has nothing to do with the enterprise culture and strategy, managers find it difficult to keep the supervision effectively. In addition, the development of network communication platform is a bottomup model. It takes the primary level as its center, in conflict with most of the information communication modes of enterprise management. If the opinions of the primary level are accepted, it will have a great influence on the speed of knowledge sharing, working enthusiasm and sense of belonging to the enterprise. Finally, the employees spend a lot of time in the network communication platforms. The habit of paying attention to people and things in the virtual world might reduce work performance.

\section{Conclusion and Prospect}

We cannot directly copy the western experience. In the United States, Linkedin and Facebook are relatively independent customer bases, with business circles and social circles being relatively independent. However, in China, the fusion degree of the two is higher.

Randstad Group data of 2011/2012 work world report shows that $85 \%$ of enterprise respondents believed social network would become an important tool of attracting talent. Human resource management should timely grasp new opportunities that social networks provide, help social network and human resource management to promote each other. At the same time, enterprise should take active measures to cope with the challenges.

Firstly, the development of social networkimng promotes changes of human resource management concept. Secondly, it makes people realize the importance of human resource management. If scientific and technical level is relatively stable, management is the prime force of productivity. Human resource management with Chinese characteristics is still in the exploratory stage, but we can believe that human resource management will occupy are seat in the field of social networking, through making the full use of talents to achieve the sustained profitability of the enterprise.

Thirdly, social networking has changed the macro environment of human resources and increased the difficulty of vertical management. This needs strengthening the function of informal groups created in social networks, and give the positive guidance to enhance employees' sense of belonging. In addition, it is necessary to improve the relevant management mechanism, cultivate the enterprise's shared culture, and make it consistent with the values of its employees. Reasonable use of social networking can reduce the efficiency loss caused by asymmetric information. This is conductive to establish a twoway trust mechanism, especially the trust that comes from low level to high level. The human resource management has to take measures to encourage employees to participate actively in the enterprise internal communication platform.

Finally, social networks can strengthen staff training at low costs, improve employees' professional morals, and spread positive enterprise culture. Once employees put forward their suggestions, the enterprise must give the 
appropriate reward to motivate them for proposals and participation. The human reasource management must make full use of the positive impacts that come from enterprise communication platforms and online games to achieve low-cost communication, learning and training. It is important to introduce innovation in management, including enterprise incentive mechanism and constraint mechanism.

Jobvite's recruiting data shows that a candidate who has been ranked by every ten employees can be hired but only one out of every low-ranked candidates can get the job. To encourage employees to give recommendations to their fellows, many enterprises undertake training activities from the first day at work. For example, in Yelp, the new employee-training program helps them understand the value of internal recommendations and emphasize everyone's role in this process.

\section{References}

1. Zhao Y., Tan Z. Electronic Commerce, Bank Credit and SME Financing, Economic Research, 2012, no. 7, pp. 99-112.

2. Chen D. Cross-Cultural Communication Network and Human Resource Management, Seeker, 2008, no. 3, pp. 76-78.

3. Liang D. Talking about Human Resources Management of Enterprises in Network Era, SCI/TECH Information Development \& Economy, 2003, no. 3, pp. 146-147.

4. Wu Y. Social Network Games Change Human's Life, Journal of Beijing University of Posts and Telecommunications, 2012, no. 1, pp. 7-11.

5. Yi Chengang. The Application of Social Network in the Recruitment, NONFERR METAL SOC, 2012, no. 16, pp. 58-59.

6. Liang J. Research on Human Resource Management from the Perspective of Boundaryless Theory, Human Resource Development of China, 2013, no. 19, pp. 15-19.

7. Wang M., Zhang W., Zhou Li-an. Information Technology, Organization Innovation, and Productivity: Evidence on the Phase Characteristics of Complementarities, Economic Research, 2006, no. 1, pp. 65-77.

8. Chen D., Fan C., Shen Y., Zhou Y. Employee Incentive, Wage Rigidity and Firm Performance: Empirical Evidence from Chinese Unlisted SOEs, Economic Research, 2010, no. 7. pp. 116-129.

\section{Список литературы}

1. Zhao, Y. Electronic Commerce, Bank Credit and SME Financing / Y. Zhao, Z. Tan // Economic Research. - 2012. - No. 7. - P. 99 - 112.

2. Chen, D. Cross-Cultural Communication Network and Human Resource Management / D. Chen // Seeker. - 2008. - No. 3. - P. 76 - 78.

3. Liang, D. Talking about Human Resources Management of Enterprises in Network Era / D. Liang // SCI/TECH Information Development \& Economy. - 2003. No. 3. - P. $146-147$.

4. Wu, Y. Social Network Games Change Human's Life / Y. Wu // Journal of Beijing University of Posts and Telecommunications. - 2012. - No. 1. - P. $7-11$.

5. Yi, Chengang. The Application of Social Network in the Recruitment / Yi Chengang // NONFERR METAL SOC. - 2012. - No. 16. - P. 58 - 59. 
6. Liang, J. Research on Human Resource Management from the Perspective of Boundaryless Theory / J. Liang // Human Resource Development of China. - 2013. No. 19. - P. 15 - 19.

7. Wang, M. Information Technology, Organization Innovation, and Productivity: Evidence on the Phase Characteristics of Complementarities / M. Wang, W. Zhang, Li-an Zhou // Economic Research. - 2006. - No. 1. - P. 65 - 77.

8. Employee Incentive, Wage Rigidity and Firm Performance: Empirical Evidence from Chinese Unlisted SOEs / D. Chen [et al.] // Economic Research. - 2010. - No. 7. P. $116-129$.

\section{Профессиональные социальные сети и их влияние на организацию работы предприятий по управлению кадрами}

\section{М. Шень}

Школа экономики, Шаньдунский педагогический университет, Цзинань, Китайская народная республика

Ключевые слова: профессоинальные социальные сети; управление человечскими ресурсами; эффективность предприятия.

Аннотация: Представлено профессиональное сетевое взаимодействие - эффективный инструмент управления человеческими ресурсами предприятия. Рассмотрена специфика организации работы предприятия с использованием социальных сетей. Отмечены положительные и отрицательные факторы, влияющие на организацию управления человеческими ресурсами: подбор кадров, межкультурная взаимодействие, оценка результатов работы, формирование команды.

(C) М. Шень, 2016 